American Journal of Pharmacology and Toxicology 5 (1): 14-23, 2010

ISSN 1557-4962

(C) 2010 Science Publications

\title{
Hypolipidemic Effects of Coenzyme Q10 in Experimentally Induced Hypercholesterolemic Model in Female Rats
}

\author{
Atef M. Al-Attar \\ Department of Biological Sciences, Faculty of Sciences, \\ King Abdul Aziz University, Jeddah, Saudi Arabia
}

\begin{abstract}
Problem statement: Hyperlipidemia is well known to play a main role in the development of atherosclerosis. It is characterized by abnormally elevated cholesterol, triglyceride, low density lipoprotein cholesterol and very low density lipoprotein cholesterol levels in the blood. It has been recognized for many years that hypercholesterolemia is a major risk factor for cardiovascular diseases such as atherosclerosis, myocardial infraction, heart attacks and cerebrovascular diseases. In recent years, Coenzyme Q10 has gained considerable attention as a dietary supplement capable of influencing cellular bioenergetics and as a supplementary treatment for some chronic diseases. Approach: The present study was undertaken to evaluate whether Coenzyme Q10 supplementation would alter high cholesterol dietinduced hypercholesterolemic model in female rats. Sixty female albino rats of the Wistar strain weighing between 34.3 and $42.1 \mathrm{~g}$ were used. The experimental animals were divided into six groups. Rats of group 1 served as controls, fed with standard diet and had free access to water for three months. Rats of group 2 were daily supplemented with $1 \mathrm{~mL}$ of corn oil containing $10 \mathrm{mg}$ of cholesterol/rat for two months. Animals of group 3 were daily supplemented with $1 \mathrm{~mL}$ of corn oil containing $10 \mathrm{mg}$ of cholesterol/rat for two months and daily supplemented with $1 \mathrm{mg}$ Coenzyme Q10/rat at third month. Rats of group 4 were daily supplemented with $1 \mathrm{~mL}$ of corn oil /rat for two months. The experimental rats of group 5 were daily supplemented with $1 \mathrm{~mL}$ of corn oil /rat for two months and daily supplemented with $1 \mathrm{mg}$ Coenzyme Q10/rat at third month. Rats of group 6 were supplemented with $1 \mathrm{mg}$ Coenzyme Q10/rat at third month. The body weight percentage changes were determined after second and third months in all experimental groups. Results: After 2 months, the maximum changes of body weight were noted in groups treated with high cholesterol diet and corn oil. After three months, the maximum percentage changes were observed in groups two and four and the minimum changes were noted in sixth group supplemented with only Coenzyme Q10 at last period. Serum triglycerides, cholesterol, High Density Lipoprotein Cholesterol (HDL-C), Low Density Lipoprotein Cholesterol (LDL-C), Very Low Density Lipoprotein Cholesterol (VLDL-C), Atehrogenic Index (AI) and HDL Cholesterol (HDL-C) ratio were assessed at the end of experimental period. Significant increases in the levels of triglycerides, cholesterol, LDL-C VLDL-C were noted in rats supplemented with high cholesterol diet, while the level of HDL-C was significantly reduced. Similar observations were noted in rats treated with high cholesterol diet plus Coenzyme Q10. Statistically, the treatment of Coenzyme Q10 in rats subjected to high cholesterol diet showed a decrease in the change levels of these parameters. Also, the Atehrogenic Index (AI) value was significantly elevated in rats supplemented with high cholesterol diet compared with control value. Administration of Coenzyme Q10 for a period of one month to rats supplemented with high cholesterol diet significantly decreased the percentage change of the Atehrogenic Index (IA) value. HDL-C ratio value was significantly decreased in rats supplemented with high cholesterol diet compared with control value. Treatment with Coenzyme Q10 for a period of last month significantly decreased the percentage change of the HDL-C ratio value in rats fed with high cholesterol diet. Conclusion: The present results suggested that Coenzyme Q10 possesses hypolipidemic effects in rats supplemented with high cholesterol diet. Thus, use of Coenzyme Q10 may be useful in the treatment of cardiovascular diseases in which atherosclerosis plays a major role.
\end{abstract}

Key words: High cholesterol diet, Coenzyme Q10, lipid profile, rats

\section{INTRODUCTION}

The World Health Organization (WHO) estimates that every year 12 million people worldwide die from cardiovascular diseases, with most of them being from the developing world (Kmietowicz, 2002). Most people would benefit from lowering their blood pressure and cholesterol level. It has been recognized for many years 
that hypercholesterolemia is a major risk factor for cardiovascular diseases such as atherosclerosis, myocardial infraction, heart attacks and cerebrovascular diseases (Wald and Law, 1995). The increased blood levels of total cholesterol, Low Density Lipoprotein Cholesterol (LDL-C) and Very Low Density Lipoprotein Cholesterol (VLDL-C) as well as lowered levels of High Density Lipoprotein Cholesterol (HDLC) has been identified in development of hypercholesterolemia (Ross, 1999). People who are predisposed to a combination of risk factor (dietary habits, genetic susceptibility, age, diabetes and smoking) are more prone to develop hypercholesterolemia (Ashakumary and Vijammal, 1993). Additionally, hyperlipidemia with increased concentrations of cholesterol and triglyceride-carrying lipoproteins is considered to be the cause of arteriosclerosis, with its dual sequelae of thrombosis and infarction. Elevated lipid levels, especially hypercholesterolemia, result from increased absorption from the gut or endogenous synthesis. Diet-induced hypercholesterolemia has long been useful for the assessment of agents interfering with the absorption, degradation and excretion of cholesterol, rather than interfering with cholesterol biosynthesis. Indeed, many animal species have been used in experiments to evaluate the hypercholesterolemic effect of highcholesterol and high-fat diet (Beere et al., 1992; Ramirez-Tortosa et al., 1999; Hsu and Yen, 2007; Zulkhairi et al., 2008; Kanashiro et al., 2009; Kim et al., 2009; Shimoda et al., 2009).

Coenzyme Q10 (2,3 dimethoxy-5methyl-6decarpenyl benzoquinone) is a fat-soluble, vitamin-like quinine commonly known as ubiquinone, CoQ and vitamin Q10 (Greenberg and Frishman, 1990; Tran et al., 2001). Coenzyme Q10 is a ubiquitous compound vital to a number of activities related to energy metabolism. Because dysfunctional energy metabolism has been cited as a contributing factor for a number of conditions. Normal blood and tissue levels of Coenzyme Q10 have been well established by numerous investigators around the world. Significantly decreased levels of Coenzyme Q10 have been noted in a wide variety of diseases in both animal and human studies. Coenzyme Q10 deficiency may be caused by insufficient dietary Coenzyme Q10, impairment in Coenzyme Q10 biosynthesis, excessive utilization of Coenzyme Q10 by the body, or any combination of the three. Decreased dietary intake is presumed in chronic malnutrition and cachexia (Littarru et al., 1991). Coenzyme Q10 has been indicated in the treatment of cardiac, neurologic, oncologic and immunologic disorders (Barbieri et al., 1999; Mortensen, 2003;
Spindler et al., 2009; Mancuso et al., 2010). Coenzyme Q10 is a vital for the proper transfer of electrons within the mitochondrial oxidative respiratory chain, whose main function is adenosine triphosphate (ATP) production. Coenzyme Q10 also appears to increase adenosine triphosphate levels by preventing the loss of adenine nucleotide pool from cardiac cells (Ito et al., 1991). Additionally, Coenzyme Q10 has demonstrated activity in preventing lipid peroxidation as an antioxidant scavenger and an indirect stabilizer of calcium channels to decrease calcium overload (Nayler, 1980; Sugiyama et al., 1980). In recent years, Coenzyme Q10 (CoQ10) has gained considerable attention as a dietary supplement capable of influencing cellular bioenergetics and counteracting some of the damage caused by free radicals (Linnane et al., 2002; Butler et al., 2003; Rosenfeldt et al., 2003; Zhou et al., 2005; Cooke et al., 2008).

In the past 50 years the driving force in medicine has been the development of drugs and procedures to modify the pathophysiology of illness. As viewed from the trenches of medical practice, the advances in drug therapy, although notable and clearly helpful, appear to have reached a plateau. Most of the "new" drugs over the past several years are primarily variants of old drugs. By comparison, the impressive advances made by basic scientists, biochemists and molecular biologists, are only now beginning to be appreciated by the medical profession and the enormous potential of these basic science advances has yet to be pursued.

Modern medicine seems to be based on an "attack strategy", a philosophy of treatment formed in response to the discovery of antibiotics and the development of surgical/anesthetic techniques. Disease is viewed as something that can be attacked selectively-with antibiotics, chemotherapy, or surgery-assuming no harm to the host. Even chronic illnesses, such as diabetes and hypertension, yield simple numbers which can be furiously assaulted with medications. Amidst the miracles and drama of 20th century medicine we may have forgotten the importance of host support, as if time borrowed with medications and surgery were restorative in and of itself. Yet, in this age, a patient may be cured of leukemia through multiple courses of chemotherapy and bone marrow transplantation, only to die slowly of unrecognized thiamine (vitamin B1) deficiency (Pihko et al., 1989). Like the vitamins discovered in the early part of the twentieth century, Coenzyme Q10 is an essential element of food that can now be used medicinally to support the sick host in conditions where nutritional depletion and cellular dysfunction occur. Surely, the combination of disease attacking strategy and host supportive treatments would yield much better results in clinical medicine. 
Since Coenzyme Q10 is essential to the optimal function of all cell types, it is not surprising to find a seemingly diverse number of disease states which respond favorably to Coenzyme Q10 supplementation. All metabolically active tissues are highly sensitive to a deficiency of Coenzyme Q10. Coenzyme Q10's function as a free radical scavenger only adds to the protean manifestations of Coenzyme Q10 deficiency. Preliminary observations in a wide variety of disease states have already been published (Hansen et al., 1976; Cortes et al., 1977; Combs et al., 1981; Iwamoto et al., 1981; Judy et al., 1983; Folkers et al., 1988; 1993; Langsjoen et al., 1991; Lockwood et al., 1994a; 1994b 1995).

One of the disease states which has received attention is cancer. Low levels of Coenzyme Q10 in the blood of some cancer patients have been noted (Mellstedt et al., 1994), but overall, there is little data regarding cancer. The best work to date documents a significant reduction in the cardiac toxicity of the chemotherapy drug, Adriamycin (Cortes et al., 1977; Combs et al., 1981; Iwamoto et al., 1981; Judy et al., 1983). The cardiac toxicity of Adriamycin and related drugs may well relate to free radical generation and this might explain the benefit of Coenzyme Q10 in its capacity as a free radical scavenger. The studies on Adriamycin cardiotoxicity were of short duration and did not specifically note any favorable or detrimental effect on the clinical course of the cancer itself. It is reasonable to assume that optimal nutrition (which would include optimal levels of Coenzyme Q10) is generally beneficial in any disease state, including cancer.

Another interesting topic is the relationship between the immune system and Coenzyme Q10. Immune function is extraordinarily complex and undoubtedly is influenced by numerous nutritional variables. There are some encouraging preliminary data from the study of AIDS patients (Judy et al., 1983; Folkers et al., 1988). End stage AIDS, like other overwhelming illnesses, has been associated with a significant deficiency in Coenzyme Q10. Regarding AIDS and cancer, it would be foolish to make premature statements about future utility of CoQ10, but it is even more foolish to ignore the importance of adequate Coenzyme Q10 levels in these disease states. Adequate Coenzyme Q10 supplementation (with close attention to plasma CoQ10 levels) is analogous to adequate hydration and any treatment of critically ill patients should not ignore this easily measured and correctable deficiency.

The antioxidant or free radical quenching properties of Coenzyme Q10 serve to greatly reduce oxidative damage to tissues as well as significantly inhibit the oxidation of LDL-C (much more efficiently than vitamin E) (Ingold et al., 1993; Bowry et al., 1995). This has great implications in the treatment of ischemia and reperfusion injury as well as the potential for slowing the development of atherosclerosis. In keeping with the free radical theory of aging, these antioxidant properties of Coenzyme Q10 have clear implications in the slowing of aging and age related degenerative diseases. There is epidemiologic evidence in humans that uniformly shows a gradual decline in Coenzyme Q10 levels after the age of twenty. Until recently, attention has been focused on requirements for Coenzyme Q10 in energy conversion in the mitochondrial compartment of cells or on the antioxidant properties of Coenzyme Q10. New evidence shows that Coenzyme Q10 is present in other cell membranes. In the outer membrane it may contribute to the control of cell growth, especially in lymphocytes (Linnane et al., 1992; Martnius et al., 1993; Sun et al., 1992; Lawen et al., 1994). On the basis of above mentioned studies, Coenzyme Q10 would also be expected to play a protective role against hypercholesterolemia. The induction of hypercholesterolemia by a high cholesterol diet in experimental animals including rats has been suggested. In addition, diet-induced hypercholesterolemia has long been useful for the assessment of agents with beneficial effects on cholesterol regulation. Therefore, the present study was carried out to determine the protective potential of Coenzyme Q10 on lipid profile in experimentally induced hypercholesterolemic model in female rats.

\section{MATERIALS AND METHODS}

Experimental design: Healthy sixty female albino rats of the Wistar strain (34.3-42.1 g) used in this study were obtained from the Experimental Animal Unit of King Fahd Medical Research Center, King Abdul Aziz University, Jeddah, Saudi Arabia. The experimental animals were housed 5 per cage in a room with $12 / 12 \mathrm{~h}$ light/dark cycle at ambient temperature of $19 \pm 1^{\circ} \mathrm{C}$. The rats were randomly distributed into six groups of 10 each. Rats of group 1 served as controls, fed with standard diet and had free access to water for three months. The animals of group 2 were fed with standard diet and daily supplemented with $1 \mathrm{~mL}$ of corn oil containing $10 \mathrm{mg}$ of cholesterol/rat for two months. Rats of group 3 were fed with standard diet and daily supplemented with $1 \mathrm{~mL}$ of corn oil containing $10 \mathrm{mg}$ of cholesterol/rat for two months and daily supplemented with $1 \mathrm{mg}$ Coenzyme Q10/rat at third month. Animals of group 4 were fed with standard diet 
and daily supplemented with $1 \mathrm{~mL}$ of corn oil /rat for two months. Rats of group 5 were fed with standard diet and daily supplemented with $1 \mathrm{~mL}$ of corn oil /rat for two months and daily supplemented with $1 \mathrm{mg}$ Coenzyme Q10/rat at third month. The experimental animals of group 6 were fed with standard diet and daily supplemented with $1 \mathrm{mg}$ Coenzyme Q10/rat at third month. The body weight changes of the experimental animals were measured at the start of the experimental periods, after two and three months using a digital balance. These weights were determined at the same time during the morning and the percentage changes of body weight after two and three months were calculated. Also, after three months, the experimental rats were fasted for $10 \mathrm{~h}$, water was not restricted and then anaesthetized with ether. Blood samples were collected from orbital venous plexus in non-heparinized tubes, centrifuged at $2000 \mathrm{rpm}$ for 20 min. and blood sera were then collected and stored at $4^{\circ} \mathrm{C}$ prior immediate determination of triglycerides, cholesterol, HDL-C, LDL-C and VLDL-C. All of these parameters were measured using Automated Clinical Chemistry Analysis System, Dimension ${ }^{\circledR}$ type RXL Max (Dade Behring Delaware, DE 19714, USA). Atherogenic Index (AI) values were determined following the method of Pandya and Jain (2006). HDLCholesterol (HDL-C) ratio was calculated using the following equation:

\section{HDL-C ratio $=$ HDL-C $\times 100 /$ total serum cholesterol- HDL-C}

Statistical analysis: All data were analyzed using the Statistical Package for Social Sciences (SPSS for windows, version 12.0). Each value is expressed as mean \pm SD and values were analyzed by ANOVA to determine differences between the mean values of experimental groups. p-values of less than 0.05 were considered significant.

\section{RESULTS}

Figure 1 shows the body weight percentage changes after two and 3 months in all experimental groups. After two months, the maximum changes were noted in groups 2 (343.88\%), 3 (348.91\%), 4 (351.76\%) and $5(347.75 \%)$ treated with high cholesterol diet and corn oil. Moreover, the percentage changes in groups 1 and 6 supplemented with normal diet for two months were 317.42 and $315.30 \%$ respectively. After 3 months, the percentage change in control group was $317.89 \%$. The percentage changes in groups 2 and 4 supplemented with standard diet for last month were $423.96 \%$ and $380.54 \%$ respectively. The percentage changes in groups 3 and 5 supplemented with Coenzyme Q10 at third month were $387.68 \%$ and $379.63 \%$ respectively. Also, the minimum changes were observed in group 6 supplemented with only Coenzyme Q10 at last month.

Measured values at the end of experimental period for serum triglycerides, cholesterol, HDL-C, LDL-C and VLDL-C in female rats treated with high cholesterol diet, high cholesterol diet plus Coenzyme Q10, corn oil, corn oil plus Coenzyme Q10 and Coenzyme Q10 are given in Table 1. There were significant increases in the levels of triglycerides $(+208.89 \%)$, cholesterol $(+228.82 \%)$, LDL$\mathrm{C}(+554.68 \%)$ and VLDL-C $(+208.83 \%)$ in rats supplemented with high cholesterol diet, while the level of HDL-C (-38.78\%) was significantly reduced. Similar observations were noted in rats treated with high cholesterol diet plus Coenzyme Q10. Statistically, the treatment of Coenzyme Q10 in rats subjected to high cholesterol diet showed a decrease in the change levels of triglycerides $(+49.33 \%)$, cholesterol $(+69.66 \%)$, LDL-C $(+212.72 \%)$, VLDL-C $(+49.29 \%)$ and HDL-C $(-26.28 \%)$ when compared with to that cause by high cholesterol diet. In comparison with control group, there were no significant changes in the values of serum triglycerides, cholesterol, HDL-C, LDL-C and VLDL-C in female rats treated with corn oil, corn oil plus Coenzyme Q10 and Coenzyme Q10.

As shown in Fig. 2, the atehrogenic index (AI) value was significantly elevated $(663.12 \%)$ in rats supplemented with high cholesterol diet compared with control value. Administration of Coenzyme Q10 for a period of one month to rats supplemented with high cholesterol diet significantly decreased the percentage change $(214.89 \%)$ of the Atehrogenic Index (AI) value. Result showed that there were no significant differences in the values of Atehrogenic Index (AI) in rats treated with corn oil, corn oil plus Coenzyme Q10 and Coenzyme Q10. The HDL-C ratio value was significantly decreased $(89.60 \%)$ in rats supplemented with high cholesterol diet compared with control value.

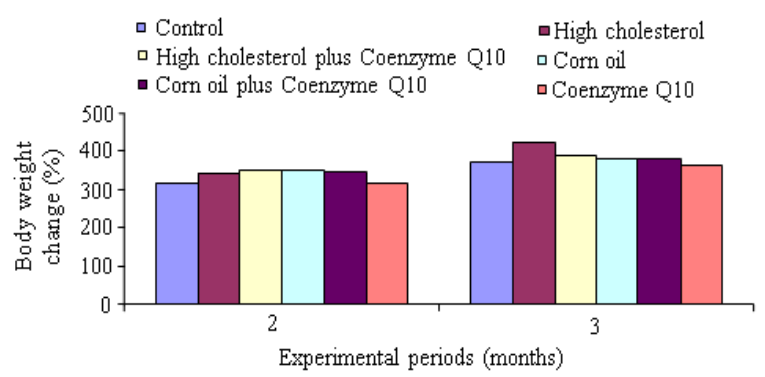

Fig. 1: The body weight percentage changes after 2 and 3 months in all experimental groups. 
Am. J. Pharm. \& Toxicol., 5 (1): 14-23, 2010

Table 1: The values of serum triglycerides, cholesterol, HDL-C, LDL-C and VLDL-C in female rats treated with high cholesterol diet, high cholesterol diet plus Coenzyme Q10, corn oil, corn oil plus Coenzyme Q10 and Coenzyme Q10 $(\mathrm{n}=10)$. Percentage changes are included in parentheses. A indicates a significant difference between control and treated groups. $\mathrm{b}$ indicates a significant difference between the group supplemented with high cholesterol diet and the groups treated with high cholesterol diet plus Coenzyme Q10, corn oil, corn oil plus Coenzyme Q10 and Coenzyme Q10

\begin{tabular}{|c|c|c|c|c|c|}
\hline Treatment & $\begin{array}{l}\text { Triglycerides } \\
\left(\mathrm{mg} 100 \mathrm{~mL}^{-1}\right)\end{array}$ & $\begin{array}{l}\text { Cholesterol } \\
\left(\mathrm{mg} 100 \mathrm{~mL}^{-1}\right)\end{array}$ & 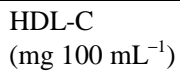 & $\begin{array}{l}\text { LDL-C } \\
\left(\mathrm{mg} 100 \mathrm{~mL}^{-1}\right)\end{array}$ & $\begin{array}{l}\text { VLDL-C } \\
\left(\mathrm{mg} 100 \mathrm{~mL}^{-1}\right)\end{array}$ \\
\hline Control & $59.60 \pm 3.41$ & $79.10 \pm 3.81$ & $39.20 \pm 2.83$ & $27.98 \pm 5.45$ & $27.41 \pm 1.5$ \\
\hline High cholesterol & $184.10 \pm 21.47^{\mathrm{ab}}$ & $260.10 \pm 28.73^{\mathrm{ab}}$ & $24.00 \pm 3.68^{\mathrm{ab}}$ & $183.18 \pm 58.44^{\mathrm{ab}}$ & $\begin{array}{l}84.65 \pm 9.87^{\mathrm{ab}} \\
(+208.83 \%\end{array}$ \\
\hline High cholesterol + & $89.00 \pm 11.29^{\mathrm{a}}$ & $134.20 \pm 20.13^{\mathrm{a}}$ & $28.90 \pm 2.64^{\mathrm{a}}$ & $87.50 \pm 20.46^{\mathrm{a}}$ & $40.92 \pm 5.19^{\mathrm{a}}$ \\
\hline Coenzyme Q10 & $(+49.33 \%)$ & $(+69.66 \%)$ & $(-26.28 \%)$ & $(+212.72 \%)$ & $(+49.29 \%)$ \\
\hline Corn oil & $\begin{array}{l}64.20 \pm 5.65 \\
(+7.72 \%)\end{array}$ & $\begin{array}{l}81.20 \pm 4.45 \\
(+2.66 \%)\end{array}$ & $\begin{array}{l}37.90 \pm 3.41 \\
(-3.32 \%)\end{array}$ & $\begin{array}{l}30.06 \pm 7.51 \\
(+7.43 \%)\end{array}$ & $\begin{array}{l}29.25 \pm 2.60 \\
(+6.71 \%)\end{array}$ \\
\hline Corn oil + Coenzyme Q10 & $\begin{array}{l}62.00 \pm 5.38 \\
(+4.03 \%)\end{array}$ & $\begin{array}{l}79.90 \pm 5.43 \\
(+1.01 \%)\end{array}$ & $\begin{array}{l}38.00 \pm 2.21 \\
(-3.06 \%)\end{array}$ & $\begin{array}{l}29.70 \pm 5.83 \\
(+6.15 \%)\end{array}$ & $\begin{array}{l}28.51 \pm 2.47 \\
(+4.01 \%)\end{array}$ \\
\hline Coenzyme Q10 & $\begin{array}{l}58.90 \pm 3.37 \\
(-1.18 \%)\end{array}$ & $\begin{array}{l}76.30 \pm 4.03 \\
(-3.54 \%)\end{array}$ & $\begin{array}{l}38.70 \pm 2.87 \\
(-1.28 \%)\end{array}$ & $\begin{array}{l}26.12 \pm 6.33 \\
(-6.65 \%)\end{array}$ & $\begin{array}{l}27.08 \pm 1.64 \\
(-1.20 \%)\end{array}$ \\
\hline
\end{tabular}

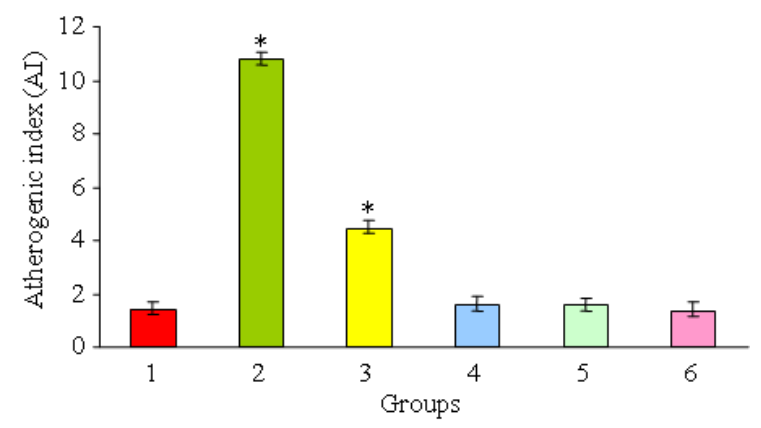

Fig. 2: Atherogenic index (AI) values after 3 months in groups 1(control), 2 (high cholesterol), 3 (high cholesterol plus Coenzyme Q10), 4 (corn oil), 5 (corn oil plus Coenzyme Q10) and 6 (Coenzyme Q10).

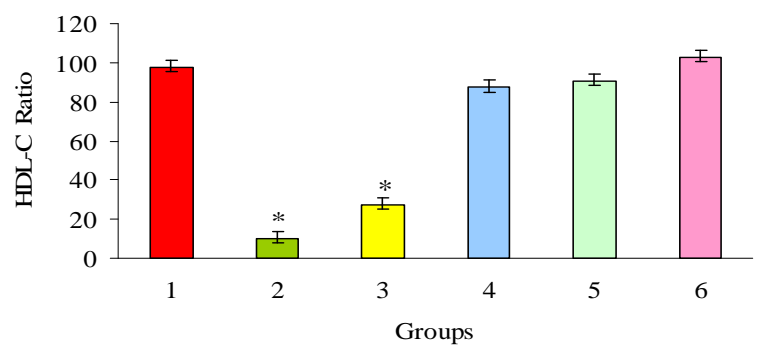

Fig. 3: HDL-C ratio after 3 months in groups 1(control), 2 (high cholesterol), 3 (high cholesterol plus Coenzyme Q10), 4 (corn oil), 5 (corn oil plus Coenzyme Q10) and 6 (Coenzyme Q10).

Treatment with Coenzyme Q10 for a period of last month significantly decreased the percentage change (71.92\%) of the HDL-C ratio value in rats fed with high cholesterol diet. Moreover, there were no significant differences in the values of HDL-C ratio in experimental animals supplemented with corn oil, corn oil plus Coenzyme Q10 and Coenzyme Q10 (Fig. 3).

\section{DISCUSSION}

In the present investigation, noticeably increases of body weight were detected in high cholesterol and corn oil treated rats compared with control value. Similar observations were reported in several studies (He et al., 2008; Amin and Nagy, 2009; Koya-Miyata et al., 2009; Lee et al., 2009; Bhalodia et al., 2010; Rachh et al., 2010). Administration of Coenzyme Q10 for last month inhibited the percentage change of body weight in rats treated with high cholesterol diet and con oil. Also, the minimum of body weight change was noted in rats fed with standard diet and supplemented with Coenzyme Q10 at last period. It suggests that Coenzyme Q10 decreased storage of fat as well as protein.

The present results demonstrated that cholesterol feeding in rats caused significant increases in the levels of circulating triglycerides, cholesterol, LDL-C, VLDL$\mathrm{C}$ and atehrogenic index (AI), while the values of HDL$\mathrm{C}$ and HDL-C ratio were significantly decreased. These results are consistent with many previous experimental studies (Khanna et al., 2002; Prasad, 2005; Jain and Agarwal, 2006; Vijaimohan et al., 2006; Miceli et al., 2007; Park et al., 2009; Pyo and Seong, 2009). Excessive dietary intake of fat cause serum cholesterol to rise by down regulating LDL receptor synthesis as a result of which the uptake of LDL-C via LDL receptor is reduced which result in an increase of blood cholesterol level (Dietschy et al., 1993). The National Cholesterol Education Program (NCEP) guidelines (2001) state that lowering LDL-C is the primary objective of coronary heart disease risk reduction. Consequently, there is increasing demand for a medical treatment for this problem. 
The present study showed that one month of supplementation with Coenzyme Q10 was effective in improving serum lipid profile in rats fed high cholesterol diet compared with control levels. In addition, it might also result in a reduction in the risk of atherosclerosis, because the ratio of HDL-C was significantly higher than in the rats supplemented with only high cholesterol diet. Singh et al. (2000) reported that Coenzyme Q10 decreased the aortic cholesterol, triglycerides, sudanophilia and aortic and coronary artery plaque sizes, coronary atherosclerosis index, aortic and coronary atherosclerosis scores in trans-fatty rich diet. The reduction in lipid levels and increase in HDL-C levels may be due to inhibition of LDL-C oxidation and reduce oxidative stress. Moreover, Modi et al. (2006a; 2006b) showed that the treatment with Coenzyme Q10 produced significant decreases in the elevated levels of serum cholesterol, triglycerides, VLDL-C, LDL-C and atherogenic index and increased HDL-C levels in diabetic treated rats. However, the mechanism by which Coenzyme Q10 lowered serum triglycerides is not clear but it may be possible due to either a decrease in VLDL-C synthesis or channeling of VLDL-C to pathway other than to LDL or an increase in lipoprotein lipase activity.

Oxidative stress, defined as a disruption of the balance between oxidative and antioxidative processes, plays an important role in the pathogenesis of atherosclerosis (Steinberg et al., 1989). A cholesterolrich diet results in increased lipid peroxidation by the induction of free radical production, followed by hypercholesterolemia, a major risk factor for atherosclerosis. It has been reported that hypercholesterolemic atherosclerosis is associated with an increase in tissue concentration of lipid peroxidation products, malondialdehyde and conjugated dienes (Lorgeril et al., 1994). Modi et al. (2006a) reported that Coenzyme Q10 significantly decreased the lipid peroxidation which may be due to decreased oxidative stress. Also, Modi et al. (2006b) showed that Coenzyme Q10 treatment reduced lipid peroxidation and increased antioxidant parameters like superoxide dismutase, catalase and glutathione in the liver homogenates of diabetic rats. Coenzyme Q10 supplementation was associated with significant reduction in thiobarbituric acid reactive substances, malondealdehyde and diene conjugates in coronary artery disease patients, indicating an overall decrease in oxidative stress (Singh and Niaz, 1999). However, the relationship between oxidative stress and cholesterol levels was confirmed in many studies (Pappolla et al., 2002; Balkan et al., 2004; Chang et al., 2006; Son et al., 2007; Codoñer-Franch et al., 2008; Yao et al., 2008; Nakagami et al., 2009).
Ramirez-Tortosa et al., (2008) investigated the effects of the administration of water soluble Coenzyme Q10 in the plasma and liver mitochondria of rabbits fed with a high-fat diet $(3 \%$ lard $+1.3 \%$ cholesterol $)$. They stated that the atherogenic diet enhanced lipid levels both in plasma and liver mitochondria, reduced plasma and mitochondrial concentrations of retinol and Coenzyme Q10, led to higher DNA damage in peripheral blood lymphocytes and reactive oxygen species concentration in liver mitochondria. The treatment of animals with Coenzyme Q10 reduced lipid concentration in liver mitochondria with no effect on plasma lipids, increased mitochondrial levels of alphatocopherol, restored mitochondrial Coenzyme Q10 and improved alpha-tocopherol levels in plasma. Moreover, Coenzyme Q10 supplementation reduced mitochondrial reactive oxygen species levels and decreased DNA damage in peripheral blood lymphocytes. Finally, they suggested that antioxidant therapy with Coenzyme Q10 may be used in the treatment of liver pathologies associated to the intake of high-fat, atherogenic, diets.

Diet-induced hyperlipidemia is the most relevant stimulus for the induction of atherosclerotic lesions in humans. Diet-induced hypercholesterolemia is almost always useful for the assessment of agents that interfere with absorption, degradation and excretion of cholesterol, with minimal effects on cholesterol biosynthesis. A priori, cholesterol levels in the body result from two sources: absorption from the gastrointestinal tract and endogenous de novo synthesis. The exact mechanism underlying the effects of Coenzyme Q10 on cholesterol metabolism needs to be further elucidated. The present reduction in the values of lipid profile levels may be due to (1) inhibition of hepatic cholesterol synthesis, (2) the redistribution of cholesterol from plasma to the liver by the cholesterolmetabolizing enzyme systems in the liver and (3) the control of lipids utilization.

\section{CONCLUSION}

In conclusion, lipid lowering therapy is indicated in primary and secondary prevention of cardiovascular diseases in addition to the management of all other risk factors including smoking, diabetes and obesity (Jessani et al., 2006). The deleterious effects of high blood cholesterol and the beneficial effects of lowering blood cholesterol in reducing morbidity and mortality from cardiovascular diseases are well established. Non pharmacological measures like dietary restriction and exercise may help in lowering blood cholesterol levels. When such therapy fails and in patients with abnormally high blood cholesterol levels, drug therapy 
is indicated (NCEP, 2001). The available drugs like statins, fibrates and nicotinic acid, though very effective, have a spectrum of adverse effects and are costly. The reason for interest in Coenzyme Q10 was the very low toxicity and the hope that it might be additive with other cholesterol lowering regimes. Thus, use of Coenzyme Q10 may be useful in the treatment of cardiovascular diseases in which atherosclerosis plays a major role. Further studies are required to establish the efficacy of Coenzyme Q10 as hypolipidemic factor.

\section{REFERENCES}

Amin, K.A. and M.A. Nagy, 2009. Effect of Carnitine and herbal mixture extract on obesity induced by high fat diet in rats. Diabetol. Metab. Syndr., 1: 17. http://www.ncbi.nlm.nih.gov/pubmed/19835614

Ashakumary, A. and P.L. Vijammal, 1993. Additive effect of alcohol and nicotine on lipid metabolism in rats. Indian J. Exp. Biol., 31: 270-274. http://www.ncbi.nlm.nih.gov/pubmed/8500841

Balkan, J., S.D. Ru-Abbasoglu, G. Aykac-Toker and M. Uysal, 2004. The effect of a high cholesterol diet on lipids and oxidative stress in plasma, liver and aorta of rabbits and rats. Nutr. Res., 24: 229-234. DOI: 10.1016/j.nutres.2003.10.005

Barbieri, B., B. Lund, B. LundstrÖm and F. Scaglione, 1999. Coenzyme Q10 administration increases antibody titer in hepatitis B vaccinated volunteers-a single blind placebo-controlled and randomized clinical study. Biofactors, 9: 351-317. http://www.ncbi.nlm.nih.gov/pubmed/10416052

Beere, P.A., S. Glagov and Ch.K. Zarins, 1992. Experimental atherosclerosis at the carotid bifurcation of the cynomolgus monkey. Arterioscl. Thrombos., 12: 1245-53. http://www.ncbi.nlm.nih.gov/pubmed/1420083

Bhalodia, Y.S., N.R. Sheth, J.D. Vaghasiya and N.P. Jivani, 2010. Hyperlipidemia enhanced oxidative stress and inflammatory response evoked by renal ischemia/reperfusion injury. Int. J. Pharmcol., 6: 25-30. DOI: 10.3923/ijp.2010.25.30

Bowry, V.W., D. Mohr, J. Cleary and R. Stocker, 1995. Prevention of tocopherol-mediated peroxidation in ubiquinol-10-free human low density lipoprotein. J. Biol. $\quad$ Chem., 270: 5756-5763. http://www.ncbi.nlm.nih.gov/pubmed/7890704

Butler, M.G., M. Dasouki, D. Bittel, S. Hunter and A. Naini et al., 2003. Coenzyme Q10 levels in Prader-Willi syndrome: Comparison with obese and non-obese subjects. Am. J. Med. Genet. A., 119: 168-171. http://www.ncbi.nlm.nih.gov/pubmed/12749057
Chang, W.C., Y.M. Yu, Y.M. Hsu, C.H. Wu and P.L. Yin et al., 2006. Inhibitory effect of Magnolia officinalis and lovastatin on aortic oxidative stress and apoptosis in hyperlipidemic rabbits. $\mathrm{J}$. Cardiovasc. Pharmacol., 47: 463-468. http://www.ncbi.nlm.nih.gov/pubmed/16633091

Codoñer-Franch, P., A.B. López-Jaén, P. Muñiz, E. Sentandren and V.V. Bellés, 2008. Mandarin juice improves the antioxidant status of hypercholesterolemic children. J. Pediatr. Gastroenterol. Nutr., 47: 349-355. http://www.ncbi.nlm.nih.gov/pubmed/18728533

Combs, A.B., D.T. Faria, S.W. Leslie and H.W. Bonner, 1981. Effect of Coenzyme Q10 on Adriamycin Induced Changes in Myocardial Calcium. In: Biomedical and Clinical Aspects of Coenzyme Q, Folkers, K. and Y. Yamamura (Eds.). Elsevier, Amsterdam, ISBN: 0444415796, pp: 137-144.

Cooke, M., M. Iosia, T. Buford, B. Shelmadine and G. Hudson et al., 2008. Effects of acute and 14-day coenzyme Q10 supplementation on exercise performance in both trained and untrained individuals. J. Int. Soc. Sports Nut., 5: 8. http://www.ncbi.nlm.nih.gov/pubmed/18318910

Cortes, E.P., G. Mohinderl, M. Pate, A. Mundia and K. Folkers, 1977. Study of Administration of Coenzyme Q10 to Adriamycin Treated Cancer Patients. In: Biomedical and Clinical Aspects of Coenzyme Q, Folkers, K. and Y. Yamamura (Eds.). Elsevier, Amsterdam, ISBN: 0444415796, pp: 267-273.

Dietschy, J.M., S.D. Turley and D.K. Spady, 1993. Role of liver in the maintenance of cholesterol and low density lipoprotein homeostasis in different animal species including humans. J. Lipid Res., 34: 1637-1659. http://www.ncbi.nlm.nih.gov/pubmed/8245716

Folkers, K., P.H. Langsjoen, Y. Nara, K. Muratsu and J. Komorowski et al., 1988. Biochemical deficiencies of coenzyme Q10 in HIV-infection and the exploratory treatment. Biochem. Biophys. Res. Commun., 153: 888-896. http://www.ncbi.nlm.nih.gov/pubmed/3382410

Folkers, K., R. Brown, W.V. Judy and M. Morita, 1993. Survival of cancer patients on therapy with coenzyme Q10. Biochem. Biophys. Res. Commun., 192: 241-245.

http://www.ncbi.nlm.nih.gov/pubmed/8476426

Greenberg, S. and W.H. Frishman, 1990. Co-enzyme Q10: A new drug for cardiovascular disease. J. Clin. $\quad$ Pharmacol., 30: 596-608. http://www.ncbi.nlm.nih.gov/pubmed/2202752 
Hansen, I.L., Y. Iwamoto, T. Kishi, K. Folkers and L.E. Thomposon, 1976. Bioenergetics in clinical medicine. IX. Gingival leucocytic deficiencies of coenzyme Q10 in patients with periodontal disease. Res. Commun. Chem. Pathol. Pharmacol., 14: 729-738. http://www.ncbi.nlm.nih.gov/pubmed/959667

He, G.W., W.J. Ou, B. Fan, R. Jing and R. He, 2008. The protective effect of Yi-Qi-Yang-Yin-Ye, a compound of traditional Chinese herbal medicine in diet-induced obese rats. Am. J. Chin. Med., 36: 705-717.

http://www.ncbi.nlm.nih.gov/pubmed/18711768

Hsu, C.L. and G.C. Yen, 2007. Effect of gallic acid on high fat diet-induced dyslipidaemia, hepatosteatosis and oxidative stress in rats. Br. J. Nutr., 98: 727-735.

http://www.ncbi.nlm.nih.gov/pubmed/17475086

Ingold, K.U., V.W. Bowry, R. Stocker and C. Walling, 1993. Autoxidation of lipids and antioxidation by alpha-tocopherol and ubiquinol in homogeneous solution and in aqueous dispersions of lipids: Unrecognized consequences of lipid particle size as exemplified by oxidation of human low density lipoprotein. Proc. Natl. Acad. Sci. USA., 90: 45-49. http://www.ncbi.nlm.nih.gov/pubmed/8419943

Ito, H., T. Nakajima, R. Takikawa, E. Hamada and M. Iguchi, et al., 1991. Coenzyme Q10 attenuates cyanide-activation of the ATP-sensitive $\mathrm{K}+$ channel current in single cardiac myocytes of the guinea-pig. Naunyn Schmiedebergs Arch. Pharmacol., 344: 133-136. http://www.ncbi.nlm.nih.gov/pubmed/1775189

Iwamoto, Y., T. Watanabe, H. Okamoto, N. Ohata and K. Folkers, 1981. Clinical Effect of Coenzyme Q10 on Periodontal Disease. In: Biomedical and Clinical Aspects of Coenzyme Q10, Folkers, K. and Y. Yamamura (Eds.). Elsevier, Amsterdam, ISBN: 0444415796, pp: 109-119.

Jain, G.C. and S. Agarwal, 2006. Favourable effect of Cleome viscosa L. on serum and hepatic lipids in hyperlipidemic rats. Asian J. Exp. Sci., 20: 331-336. ajes.in/PDFs/06-2/16-GC\%20JAIN.pdf

Jessani, S., T. Watson, F.P. Cappucio and G.Y. Lip, 2006. Prevention of cardiovascular disease in clinical practice, The Joint British Socities'(JBS2) guidelines. J. Hum. Hypertens, 20: 641-645. DOI: 10.1038/sj.jhh.1002058

Judy, W.V. J.H. H., W. Dugan, P.D. Toth and K. Folkers, 1983. Coenzyme Q10 Reduction of Adriamycin Toxicity. In: Biomedical and Clinical Aspects of Coenzyme Q, Folkers, K. and Y. Yamamura (Eds.). ISBN; 0444603807, pp: 231-241.
Kanashiro, A., D.C. Andrade, L.M. Kabeya, W.M. Turato and L.H. Faccioli et al., 2009. Modulatory effects of rutin on biochemical and hematological parameters in hypercholesterolemic golden syrian hamsters. An. Acad. Bras. Cienc., 81: 67-72. http://www.ncbi.nlm.nih.gov/pubmed/19274333

Khanna, A., F. Rizion and R. Chada, 2002. Lipid lowering activity of Phyllanthus niruri in hyperlipidemic rats. J. Ethnopharmacol., 82: 19-23. DOI: $10.1016 / \mathrm{S} 0378-8741(02)$.

Kim, M.Y., C.H. Cheong, M.H. Kim, C. Son and H.S. Yook et al., 2009. Leafy vegetable mix supplementation improves lipid profiles and antioxidant status in C57BL/6J mice fed a high fat and high cholesterol diet. J. Med. Food, 12: 877-884. http://www.ncbi.nlm.nih.gov/pubmed/19735190

Kmietowicz, Z., 2002. WHO warns of heart disease threat to developing world. BM.J., 325: 853. http://www.ncbi.nlm.nih.gov/pubmed/12386021

Koya-Miyata, S., N. Arai, A. Mizote, Y. Taniquchi and S. Ushio et al., 2009. Propolis prevents dietinduced hyperlipidemia and mitigates weight gain in diet-induced obesity in mice. Biol. Pharm. Bull., 32: 2022-2028. http://www.ncbi.nlm.nih.gov/pubmed/19952422

Langsjoen, P.H., P.H. Langsjoen, K. Folkers and P. Richardson, 1991. Treatment of Patients with Human Immunodeficiency Virus Infection with Coenzyme Q10. In: Biomedical and Clinical Aspects of Coenzyme Q, Folkers, K., G.P. Littarru and T. Yamagami (Eds.). Elsevier, Amsterdam, ISBN: 0444811524, pp: 409-415.

Lawen, A., R.D. Martinus, G. McMullen, P. Nagley and F. Vaillant et al., 1994. The universality of bioenergetic disease: The role of mitochondrial DNA mutation and the putative inter-relationship betweenmitochondria and plasma membrane NADH oxidases. Mol. Aspects Med., 15: S13-S27. http://www.ncbi.nlm.nih.gov/pubmed/7752823

Lee, J.H., C.W. Son, M.Y. Kim, H.R. Kim and E.S. Kwak et al., 2009. Red beet (Beta vulgaris L.) leaf supplementation improves antioxidant status in C57BL/6J mice fed high fat high cholesterol diet. Nutr. Res. Pract., 3: 114-121. http://www.ncbi.nlm.nih.gov/pubmed/20016711

Linnane, A.W., C. Zhang, A. Baumer and P. Nagley, 1992. Mitochondrial DNA mutation and the aging process: Bioenergy and pharmacological intervention. Mut. Res., 275: 195-208. http://www.ncbi.nlm.nih.gov/pubmed/1383761

Linnane, A.W., G. Kopsidas, C. Zhang, N. Yarovaya and S. Kovalenko et al., 2002. Cellular redox activity of coenzyme Q10: Effect of CoQ10 supplementation on human skeletal muscle. Free Radic. $\quad$ Res., 36: 445-453. http://www.ncbi.nlm.nih.gov/pubmed/12069109 
Littarru, G.P., S. Lippa, A. Oradei, R.M. Fiorni and L. Mazzanti, 1991. Metabolic and Diagnostic Implications of Blood Coq10 Levels. In: Biomedical and Clinical Aspects of Coenzyme Q, Folkers, K., T. Yamagami and G.P. Littarru (Eds.). Elsevier, Amsterdam, ISBN: 0444811524, pp: 167-178.

Lockwood, K., S. Moesgaard and K. Folkers, 1994a. Partial and complete regression of breast cancer in patients in relation to dosage of coenzyme Q10. Biochem. Biophys. Res. Commun., 199: 1504-1508. http://www.ncbi.nlm.nih.gov/pubmed/908519

Lockwood, K., S. Moesgaard, T. Hanioka and K. Folkers, 1994b. Apparent partial remission of breast cancer in 'high risk' patients supplemented with nutritional antioxidants, essential fatty acids and coenzyme Q10. Mol. Aspects Med., 15: 231-240. http://www.ncbi.nlm.nih.gov/pubmed/7752835

Lockwood, K., S. Moesgaard, T. Yamamoto and K. Folkers, 1995. Progress on therapy of breast cancer with vitamin Q10 and the regression of metastases. Biochem. Biophys. Res. Commun., 212: 172-177. http://www.ncbi.nlm.nih.gov/pubmed/7612003

Lorgeril, M., S. Renaud, N. Mamelle, P. Salen and J.L. Martin et al., 1994. Mediterranean alphalinolic acid-rich diet in secondary prevention of coronary heart disease. Lancet, 343: 1454-1459. http://www.ncbi.nlm.nih.gov/pubmed/7911176

Mancuso, M., D. Orsucci, L. Volpi, V. Calsolaro and G. Siciliano, 2010. Coenzyme q10 in neuromuscular and neurodegenerative disorders. Curr. Drug. Targets., 11: 111-121. http://www.ncbi.nlm.nih.gov/pubmed/20017723

Martnius, R.D., A.W. Linnane and P. Nagley, 1993. Growth of human namalwa cells lacking oxidative phosphorylation can be sustained by redox compounds potassium ferricyanide or coenzyme Q10 putatively acting through the plasma membrane oxidase. Biochem. Mol. Biol. Int., 31: 997-1005.

http://www.ncbi.nlm.nih.gov/pubmed/8193603

Mellstedt, H., A. Osterborg, M. Nylander, M. Morita and K. Folkers, 1994. A deficiency of coenzyme Q10 (COQ10) in conventional cancer therapy and blood levels of CoQ10 in cancer patients in Sweden. Mol. Aspects Med., 15. http://faculty.washington.edu/ely/coenzq10.html

Miceli, N., M.R. Mondello, M.T. Monforte, V. Sdrafkakis and P. Dugo et al., 2007. Hypolipidemic effects of citrus bergamia rissoet Poiteau juice in rats fed a hypercholesterolemic diet. J. Agric. Food Chem., 55: 10671-10677.

http://www.ncbi.nlm.nih.gov/pubmed/18038978
Modi, P.K, V.S. Akarma, K. Ramesh, R.K. Goyal and P.A. Bhatt, 2006a. Beneficial effects of coenzyme Q10 in streptozotocin-induced type I diabetic rats. Iran. J. Pharmacol. Therap., 5: 61-65. www.bioline.org.br/pdf?pt06010

Modi, K., D.D. Santani, R.K. Goyal and P.A. Bhatt, 2006b. Effect of coenzyme Q10 on catalase activity and other antioxidant parameters in streptozotocin-induced diabetic rats. Biol. Trace Elem. $\quad$ Res., $\quad 109$ : 25-34. http://www.ncbi.nlm.nih.gov/pubmed/16388100

Mortensen, S.A., 2003. Overview on coenzyme Q10 as adjunctive therapy in chronic heart failure. Rationale, design and end-points of "Q-symbio"-a multinational trial. Biofactors, 18: 79-89. http://www.ncbi.nlm.nih.gov/pubmed/14695923

Nakagami, H., M.K. Osako, Y. Takami, H. Hanyama and M. Mori et al., 2009. Vascular protective effects of ezetimibe in Apo e-deficient mice. Atherosclerosis, 203: 51-58. http://www.ncbi.nlm.nih.gov/pubmed/18603252

National Cholesterol Education Program Expert Panel, 2001. Summary of the third report of NCEP expert panel on detection, evaluation and treatment of high blood cholesterol in adults (Adult Treatment Panel III). J. Am. Med. Assoc., 285: 2486-2497. http://www.ncbi.nlm.nih.gov/pubmed/11368702

Nayler, W.G., 1980. The Use of Coenzyme Q10 to Protect Ischemic Heart Muscle. In: Biomedical and Clinical Aspects of Coenzyme Q, Yamamura, Y., K. Folkers and Y. Ito (Eds.). Elsevier, Amsterdam, ISBN: 0444415796, pp: 409-425.

Pandya, N.D. S. and S. Jain, 2006. Antioxidant activity of ezetimibe in hypercholesterolemic rats. Indian J. Pharmacol., 38: 205-2006. medind.nic.in/ibi/t06/i3/ibit06i3p205.pdf

Pappolla, M.A., M.A. Smith, T. Bryant-Thomas, N. Bazan and S. Petanceska et al., 2002. Cholesterol, oxidative stress and Alzheimer's disease: Expanding the horizons of pathogenesis. Free Radic. Biol. Med., 33: 173-181. http://www.ncbi.nlm.nih.gov/pubmed/12106813

Park, C.H., E.J. Cho and T. Yokozawa, 2009 Protection against hypercholesterolemia by corni fructus extract and its related protective mechanism. J. Med. $\quad$ Food, 12: 973-981. http://www.ncbi.nlm.nih.gov/pubmed/19857059

Pihko, H., U. Saarinen and A. Paetau, 1989. Wernicke encephalopathy-a preventable cause of death: Report of 2 children with malignant disease. Pediatr. $\quad$ Neurol., 5: 237-242. http://www.ncbi.nlm.nih.gov/pubmed/2679584 
Prasad, K., 2005. Hypocholesterolemic and antiatherosclerotic effect of flax lignan complex isolated from flax seed. Atherosclerosis, 179: 269-275.PMID: 15777541

Pyo, Y.H. and K.S. Seong, 2009. Hypolipidemic effects of Monascus-fermented soybean extracts in rats fed a high-fat and -cholesterol diet. J. Agric. Food Chem., 57: 8617-8622. PMID: 19697921

Rachh, P.R., M.R. Rachh, D.C. Ghadiya, K.P. Modi and N.M. Modi et al., 2010. Antihyperlipidemic activity of Gymenma sylvestre R. Br. Leaf extract on rats fed with high cholesterol diet. Int. J. Pharmacol., 6: in print. docsdrive.com/pdfs/ansinet/ijp/0000/1605916059.pdf

Ramirez-Tortosa, M.C., M.D. Mesa, M.C. Aguilera, J.L. Quiles and L. Baro et al., 1999. Oral administration of a turmeric extract inhibits LDL oxidation and has hypocholesterolemic effect in rabbits with experimental atherosclerosis. Atherosclerosis, 147: 371-78. PMID: 10559523

Ramirez-Tortosa, M.C., S. Granados, C.L. RamirezTortosa, J.J. Ochoa and P. Camacho et al., 2008. Oxidative stress status in liver mitochondria and lymphocyte DNA damage of atherosclerotic rabbits supplemented with water soluble coenzyme Q10. Biofactors, 32: 253-273. PMID: 19096124

Rosenfeldt, F., D. Hilton, S. Pepe and H. Krum, 2003. Systematic review of effect of coenzyme Q10 in physical exercise, hypertension and heart failure. Biofactors, 18: 91-100. PMID: 14695924

Ross, R., 1999. Atherosclerosis-An inflammatory disease. N. Eng. J. Med., 340: 115-126. PMID: 9887164

Shimoda, H., J. Tanaka, Y. Takahara, K. Takemoto and S.J. Shan et al., 2009. The hypocholesterolemic effects of cistanche tubulosa extract, A Chinese traditional crude medicine, in mice. Am. J. Chin. Med., 37: 1125-1138. PMID: 19938221

Singh, R.B. and M.A. Niaz, 1999. Serum concentration of lipoprotein (a) decreases on treatment with hydrosoluble coenzyme Q10 in patients with coronary artery disease: Discovery of a new role. Int. J. Cardiol., 68: 23-29. PMID: 10077397

Singh, R.B., S.N. Shinde, R.K. Chopra, M.A. Naiz and A.S. Thakur et al., 2000. Effect of coenzyme Q10 on experimental atherosclerosis and chemical composition and quality of atheroma in rabbits. Atherosclerosis, 148: 275-282. PMID: 10657562

Son, I.S., J.H. Kim, H.Y. Sohn, J.S. Kim and C.S. Kwon, 2007. Antioxidative and hypolipidemic effects of diosgenin, a steroidal saponin of yam (Dioscorea spp.) on high-cholesterol fed rats. Biosci. Biotechnol. Biochem., 71: 3063-3071. PMID: 18071250
Spindler, M., M.F. Beal and C. Henchcliffe, 2009. Coenzyme Q10 effects in neurodegenerative disease. Neuropsychiatr Dis. Treat., 5: 597-610. PMID: 19966907

Steinberg, D., S. Parthasarathy, T.E. Carew, J.C. Khoo and J.L. Witztum, 1989. Beyond cholesterol modifications of low-density lipoprotein that increase its atherogenicity. N. Engl. J. Med., 320: 915-924. PMID: 2648148

Sugiyama, S., M. Kitazawa, T. Ozawa, K. Suzuki and Y. Izawa, 1980. Anti-oxidative effect of coenzyme Q10. Experientia, 36: 1002-1003. PMID: 7439318

Sun, I.L., E.E. Sun, F.L. Crane, V.J. Morre, A. Lindgren and H. Low, 1992. Requirement for coenzyme Q in plasma membrane electron transport. Proc. Nat. Acad. Sci. U.S.A., 89: 11126-11130. PMID: 1454789

Tran, M.T., T.M Mitchell., D.T. Kennedy and J.T. Giles, 2001. Role of coenzyme Q10 in chronic heart failure, angina and hypertension. Pharmacotherapy, 21: 797-806. PMID: 11444576

Vijaimohan, K., M. Jainu, K.E. Sabitha, S. Subramaniyam and C. Anandhan et al., 2006. Beneficial effects of alpha linolenic acid rich flax seed oil on growth performance and hepatic cholesterol metabolism in high fat diet fed rat. Life Sci., 79: 448-454. PMID: 16490217

Wald, N.J. and M.R. Law, 1995. Serum cholesterol and ischaemic heart disease. Atherosclerosis, 118: S1-S5. PMID: 8821459

Yao, R.X., C.Y.H. Liao, Y. Chen, J.J. Xie and X. Yu et al., 2008. Molecular mechanisms of felodipine suppressing atherosclerosis in high-cholesterol-diet apolipoprotein E-knockout mice. J. Cardiovasc. Pharmacol., 51: 188-195. PMID: 18287887

Zhou, S., Y. Zhang, A. Davie, S. Marshall-Gradisnik and $\mathrm{H}$. $\mathrm{Hu}$ et al., 2005. Muscle and plasma coenzyme Q10 concentration, aerobic power and exercise economy of healthy men in response to four weeks of supplementation. J. Sports Med. Phys. Fitness, 45: 337-346. PMID: 16230985

Zulkhairi, A., Z. Zaiton, M. Jamaluddin, F. Sharida and T.H. Mohd et al., 2008. Alpha lipoic acid possess dual antioxidant and lipid lowering properties in atherosclerotic-induced New Zealand White rabbit. Biomed. Pharmacother., 62: 716-722. PMID: 18538528 